\title{
Epigenetics and Female Reproductive Aging
}

\author{
Isaac J. Chamani ${ }^{1}$ and David L. Keefe ${ }^{2 *}$ \\ ${ }^{1}$ NYU School of Medicine, New York, NY, United States, ${ }^{2}$ Department of Obstetrics and Gynecology, New York University \\ School of Medicine, New York, NY, United States
}

With more women than ever waiting until a more advanced age to have children, there exists a newfound urgency to identify the various implications aging has on human reproduction, and understand the disrupted biological processes that result in these changes. In this review, we focus on one recent area of study: the age related epigenetic changes that have been found in female reproductive organs, and the effect these changes may contribute to reproductive outcomes.

Keywords: DNA, infertility, aging, reproductive, epigenetics

\section{BACKGROUND}

As a result of many social and economic factors, increasing numbers of women are delaying childbirth until a more advanced age (1). Increasing maternal age has resulted in well documented decreases in fertility $(2,3)$, and increases in oocyte aneuploidy (4), and pregnancy complications (5-7). While these risks are clear, the underlying physiological processes that result in these

OPEN ACCESS

Edited by:

Lori Robin Bernstein, Pregmama, LLC, United States

Reviewed by:

T. Rajendra Kumar, University of Colorado Anschutz Medical Campus, United States Hao Chen, Guangdong University of Technology, China

${ }^{*}$ Correspondence:

David L. Keefe david.keefe@nyumc.org

Specialty section:

This article was submitted to Reproduction

a section of the journal Frontiers in Endocrinology

Received: 25 July 2018 Accepted: 28 June 2019 Published: 29 August 2019

Citation: Chamani IJ and Keefe DL (2019) Epigenetics and Female Reproductive Aging. Front. Endocrinol. 10:473. doi: 10.3389/fendo.2019.00473 outcomes are much less well defined. Proposed mechanisms involve neuroendocrine deficiency (8, 9), oocyte chromosome telomere length, meiosis abnormalities $(10,11)$, mitochondrial dysfunction $(12,13)$, as well as epigenetic modifications. Here, we discuss the epigenetic alterations associated with aging in female reproduction, and their effects on female reproduction.

\section{EPIGENETICS: A GENERAL OVERVIEW}

Epigenetics are heritable covalent modifications to DNA bases and chromatin proteins that do not alter the actual base pair sequence, but rather enhance or repress its transcription, by affecting chromatin structure and transcription factor binding (14). Epigenetics are essential to normal development and functioning $(15,16)$, and play an integral role in both normal cellular function and disease (17). Epigenetic modifications include DNA methylation, histone modifications (18), and chromatin remodeling (19).

DNA methylation (in mammals) predominantly involves adding a methyl group [S-adenosylmethionine (SAM)] to the fifth carbon position of cytosine bases in CpG dinucleotides-a cytosine followed immediately by guanine (20). DNA methyltransferase (DNMT) is the group of enzymes responsible for adding methyl groups to DNA. DNA methylation generally represses transcription of the gene, by condensing the chromatin structure and preventing transcription factors from binding, as well as by coordinating with HDAC's to decrease histone acetylation, another repressive factor (18). During cellular differentiation, however, methylation of $3^{\prime} \mathrm{CpG}$ islands has been shown to activate transcription (21). Methyl groups can be removed from DNA-demethylation-actively or passively. Active demethylation occurs via the ten-eleven translocation (TET) family of enzymes, while passive demethylation occurs during DNA replication by the lack-of-methylation of newly formed daughter strands (thereby diluting the methylation present) (22-24).

Histones are octamers comprised of two copies of each of four basic building blocks- $\mathrm{H} 2 \mathrm{~A}$, $\mathrm{H} 2 \mathrm{~B}, \mathrm{H} 3$, and $\mathrm{H} 4-$ that are wrapped in DNA forming a nucleosome. Several nucleosomes further 
wrap together and are stabilized by $\mathrm{H} 1$ linker histones (25). Histone modifications come in many forms: acetylation, methylation (mono, di, tri), phosphorylation, ubiquination, and sumoylation (26). Histone acetylation generally promotes transcription by neutralizing the histone's positive charge and thereby reducing its attraction to the negatively charged DNA, allowing the DNA to open (27). Histone acetylation occurs via the histone acetyltransferase enzyme (HAT), and deacetylation occurs via the histone deactylase enzyme (HDAC). Histone methylation can either promote or inhibit transcription depending on the methylation site $(28,29)$, and has also been shown to influence DNA methylation activity, and vice versa (30). Histone methylation occurs via histone methyl transferase (HMT), while demethylation occurs via lysine demethylase $(\mathrm{KDM})(31)$. Histone phosphorylation is an important regulator of gene transcription, and mitotic chromatin condensation (32). Phosphorylation occurs on serine, threonine, and tyrosine residues via various regulatory kinases. The mechanism by which phosphorylation achieves its effects is thought to be via altered DNA surface binding affinity (26). Histone ubiquitination involves adding a ubiquitin group-a small regulatory proteinonto histones $\mathrm{H} 2 \mathrm{~A}$ or $\mathrm{H} 2 \mathrm{~B}$. Ubiquitination requires three enzymes, E1, E2, E3, in a sequential process, and can result in transcription repression or expression, depending on the location of ubiquination (33). Finally, sumoylation is the addition of a SUMO (small ubiquitin-like modifiers) group to histones or transcription factors, via enzymes E1, E2, E3, and generally resulting in transcription repression (34).

Another very important regulator of cellular function is non-histone protein methylation. These are post-translational modifications that occur on proteins and alter their function. Methyl groups can be added onto lysine or arginine residues of specific proteins. The function of these modifications is not yet completely understood, but they are thought to affect DNA structure and function, RNA and protein synthesis and metabolism, and the cell cycle and apoptosis (35).

\section{EPIGENETIC CHANGES IN FEMALE REPRODUCTIVE AGING}

Changes in epigenetics, and epigenetic related enzymes, in oocytes of females of advanced age have been reported to include alterations to DNMT levels, DNA methylation levels, and histone acetylation and methylation patterns (Table 1).

\section{DNMT Alterations in Reproductive Aging}

DNA methyltransferase is a group of enzymes responsible for adding methyl groups to DNA (43). There are currently five DNMT's known to function in mammals, each with a slightly different function: DNMT1, DNMT2, DNMT3a, DNMT3b, and DNMT3L. There also are two types of DNA methylation that can occur: maintenance and de novo. Methylation maintenance occurs after semi-conservative DNA replication, where the newly synthesized, semi-un-methylated daughter strand, is methylated to the same pattern as the parent template strand. The new hemimethylated DNA thus becomes fully methylated. Methylation maintenance is the role of DNMT1 (20). On the other hand, when double stranded un-methylated DNA is methylated for the first time, it is known as de novo methylation. This process occurs via DNMT3a and DNMT3b (each has slightly different substrate preference) (44). DNMT3L does not itself methylate DNA, but rather it helps facilitate DNMT3a, and DNMT3b activity $(45,46)$. DNMT2 has a separate function in methylation of transfer RNA (47).

During normal development, as an oocyte develops from primordial, to primary, to secondary follicle, and then from the germinal vesicle (GV) through MII and beyond, the levels of the various types of DNMT's are in flux. DNMT1 is first expressed in the secondary follicle stage, and continues through the zygotic stage and beyond. DNMT3a is expressed beginning from the primordial stage, and DNMT3b is expressed from the primary follicle stage. DNMT2a is not detectable at any stage. DNMT3L is detected in preimplantation embryos (48). The cellular location (cytoplasmic vs. nucleic) in which the enzymes are located also changes with the different stages (49). The levels of DNMT 3a, 3b, and 3L in developing oocytes have been shown to correlate with their levels of growth and DNA methylation, associating them with a unique role in oocyte maturation (50). Furthermore, targeted gene deletions of DNMT3a or DNMT3L result in similar outcomes-embryonic death due to a failure of imprinting (epigenetic silencing of maternal or paternal DNA, that results in only one chromosome being expressed for a certain trait) caused by inadequate methylation-pointing to the essential role these enzymes play $(51,52)$. Interestingly, oocytes lacking DNMT3b do not show severe abnormality, indicating it plays a secondary role in development (53).

With aging, this pattern of DNMT regulation is altered. Experiments comparing MII oocytes from aged mice (42-45 weeks) to young mice (5-6 weeks) found altered levels of transcription of genes involved in establishing and maintaining DNA methylation, including DNMT1, DNMT3L, and higher levels of DNMT3b transcription (54). Similarly, a study using even older mice ( 66 weeks old) found reductions in transcription levels of DNMT3a (55). In another study on human oocytes from aged women, genes involved in cell cycle checkpoint and DNA damage repair and transcription showed decreased transcription (56).

Comparisons of DNMT1, DNMT3a, DNMT3b, and DNMT3L levels in MII oocytes and pre-implantation embryos ( 2 cell, 4 cell, 8 cell, and morula) showed a significant decrease in old (35-40 weeks) compared to young mice (6-8 weeks) (36). This decrease in turn reflects a broader decrease in DNA methylation found with aging in oocytes.

\section{DNA Methylation Alterations in Reproductive Aging}

DNA methylation in germ cells and early embryos is dynamic, and plays a critical role in development and growth throughout life (57). Somatic cells have stable and highly methylated DNA, which regulates their gene expression and allows them to carry out their tissue-specific functions. While mature oocytes and sperm have similarly high levels of methylation (20), they undergo dynamic changes throughout their development.

Early on, during the primordial stage, mouse germ cells undergo genome wide demethylation. Oocytes then enter meiotic 
TABLE 1 | Epigenetics, their biological function, enzymes, and changes in oocytes with advanced age.

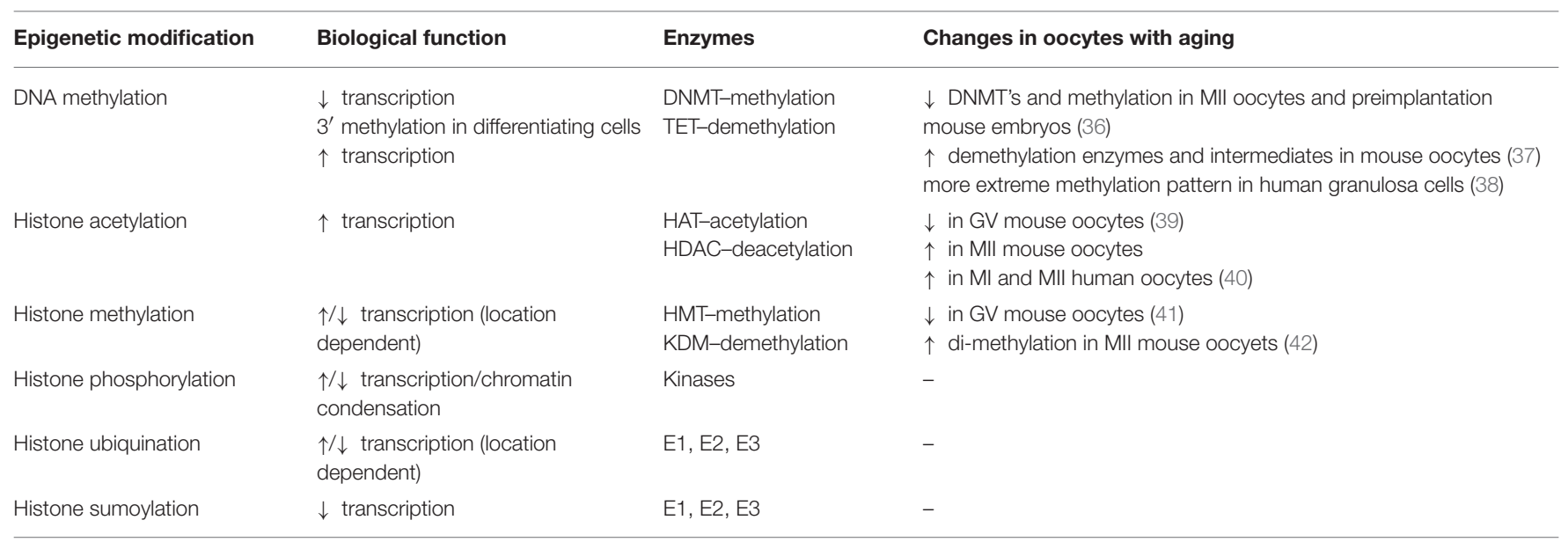

arrest, and undergo remethylation only after birth, during oocyte growth from primary to secondary follicles (58). Male germ cells replicate throughout the life of the male, and enter meiosis in the adult male. Remethylation in male germ cells occurs prenatally at the pro-spermatagonia stage.

Post fertilization, the maternal and paternal chromosomes are physically separate, and undergo different methylation changes. The paternal genome is actively-demethylated before DNA replication begins, while the maternal genome is demethylated passively (59-61). By the blastocyst stage, near the time of implantation, both genomes have again been remethylated (58). This cycle of demethylation and remethylation is important for removing parental epigenetic modifications to the germ cell genome, and for establishing totipotency in the new embryo $(15,58)$.

With maternal aging, these patterns change. By measuring 5$\mathrm{MeC}$ fluorescence intensity in MII oocytes and preimplantation embryos (2-cell, 4-cell, 8-cell, and morula), researchers showed that the level of DNA methylation in older mice (35-40 weeks) was significantly lower than that of younger mice (68 weeks). Interestingly, there was no significant difference in DNA methylation in blastocysts (36). The researchers suggested that this may be attributed to the de novo methylation which occurs via DNMT3a and DNMT3b prior to implantation. Other researchers similarly showed that in cases of advanced maternal age, embryos capable of developing to mid-gestation seem to undergo normal acquisition and maintenance of DNA methylation patterning (62).

Other research investigated the levels of DNA methylation and related gene transcription in human granulosa cells. Researchers looked at genomic DNA methylation patterns in granulosa cells of young (mean age of 26) and older (mean age of 40) women. The younger group responded robustly to ovarian stimulation during assisted reproductive technology (ART), with a mean of 25 oocytes retrieved, while the older group responded poorly with a mean of $<4$ oocytes retrieved. DNA methylome patterns between the two groups were compared using Methylated DNA Capture followed by Next Generation Sequencing (MethylCap-seq), as well as by
Reduced Representation Bisulfate Sequencing (RRBS). Their results revealed a more nuanced methylation change with aging. Regions of DNA that are more highly methylated DNA in younger females, showed increased levels of methylation with aging, and areas that were poorly methylated in younger females, showed decreased methylation with aging. With aging, then, the DNA methylation pattern shifts farther to both extremes. The researchers then sought to assess the effect this methylation difference might have on gene expression. They found 3,397 genes that were differentially expressed between the two groups, of which 1,809 were downregulated in the older group, and many of which are related to ovarian function [e.g., anti-mullerian hormone (AMH)] (38).

The flip side of DNA methylation is DNA demethylation. Intermediates of the demethylation cascade in mouse oocytes, including levels of TET enzymes as well as modified cytosine's resulting from demethylation (5-hydroxymethylcytosine, 5formylcytosine, 5-carboxylcytosine), have been found to be increased with advanced maternal age, signaling that the low DNA methylation levels observed with advanced age may result from decreased methylation, as well as increased demethylation. Furthermore, the researchers found that chemically induced accelerated aging results in different levels of demethylationpathway-intermediates than what is found in normal aging (37). This can potentially be useful in distinguishing between natural and accelerated aging, and perhaps more importantly evaluating the pace of a woman's reproductive aging and her estimated reproductive longevity.

The consequences of altered DNA methylation in advanced maternal age was recently studied, and found to result in decreased expression many important genes. Researchers used single embryo RNA-seq to examine the genetic expression of human blastocysts. They found that with increasing maternal age, there is decreased expression in over 800 genes, including many genes that are critical for cell cycle control and meiotic chromosomal segregation, and are potential causes of aneuploidy with aging (63). This, once again, highlights the important role epigenetics plays in normal reproduction. 


\section{Histone Modifications in Reproductive Aging}

Acetylation of the N-terminal tail of histones usually occurs on lysine (K) residues, and promotes transcription (29). Histone methylation can occur on either lysine or arginine residues, and can suppress or promote transcription, depending on the location. Methylation of histone $\mathrm{H} 3 \mathrm{~K} 9$ is associated with transcription suppression (64), while methylation of $\mathrm{H} 3 \mathrm{~K} 4$, or methylation of arginine on $\mathrm{H} 3$ or $\mathrm{H} 4$, is associated with transcription promotion $(28,65)$.

Like DNA methylation, histone modifications are in flux during germ cell development, and play a critical role in normal gametogenesis. In mouse oocytes at the GV stage, histone 3 lysine 9 and lysine 14 are acetylated, while on histone 4, lysines 5, 8, 12 , and 16 are acetylated (H3K9, H3K14, H4K5, H4K8, H4K12, H4K16). At MI and MII, these histones are deacetylated by HDAC with the exception of $\mathrm{H} 4 \mathrm{~K} 8(66,67)$. Histone acetylation patterns were found to be similarly well monitored (albeit to a slightly different pattern) in bovine, porcine, and sheep (68). In contrast to this, histone methylation was found to be relatively stable during oocyte maturation (69).

With maternal aging, again, these patterns shift. Research in mouse GV oocytes showed that aged (10-month-old) mice had lower levels of acetylation at H4K12 (67/81) and H4K16 (55/92) than young (2-month-old) mice (100\% for both H4K12 and H4K16) (39). Additionally, and paradoxically, at the MII stage, all oocytes from young mice were found to be completely deacetylated at $\mathrm{H} 4 \mathrm{~K} 12$, while $40 \%$ of oocytes from older mice were acetylated at H4K12 (39). Interestingly, the researchers were able to correct the aging related MII stage acetylation abnormalities by correcting the GV oocytes acetylation pattern using Trichostatin A (TSA), a histone deacetylase inhibitor.

Another study compared MII oocytes from the same mouse (to eliminate genetic interactions) at a young (3 weeks) and old age (10 months), and again found higher levels of H4K12 acetylation in the older population (70). Indeed, research indicates that $\mathrm{H} 4 \mathrm{~K} 12$ acetylation levels can potentially be used as a biomarker for oocyte quality, yielding potential clinical significance to this finding (71).

These changes can result in oocyte dysfunction and infertility. Research looking at the effect of elevated histone acetylation levels in MII mouse oocytes showed that inhibiting histone deacetylase during meiosis results in a high frequency of oocyte aneuploidy and embryo death. Another study examined the role HDAC's play in meiosis, by culturing mouse oocytes with TSA. The treated oocytes progressed through MI and MII, fertilized, and developed into blastocysts, as well as the control group did, but they subsequently had lower implantation rates, and higher miscarriage rates, than the control group. Karyotype analysis done on one cell zygotes revealed higher rates of hyper- and hypo- ploidy in the TSA treated oocytes, explaining their high rate of failure. The inhibition of histone deacetylation in oocytes led to greater rates of aneuploidy. The researchers then compared the H4K12 acetylation status of aged and young oocytes, and found them to be elevated in the aged group. They postulated that this results in an inability of the chromosome to adopt the proper conformation necessary to undergo precise segregation during meiosis, and thereby explains the increased aneuploidy rates seen with increased maternal age (72).

Another group similarly found that oocyte age correlated with abnormally elevated levels of histone acetylation on H4K12 in human MI and MII oocytes. This in turn was related to a greater propensity for chromosomes to misalign, leading to more segregation errors in older oocytes (40). In this way, the residual elevation in histone acetylation in aged oocytes at MI and MII carries a very real clinical significance.

In a similar vein, HDAC's were discovered to contribute to the stability of microtubules, and the formation of proper kinetochore-microtubule interactions, by deacetylating H4K16 and alpha tubulin, in cells undergoing meiosis. Alpha tubulin acetylation levels are important in the regulation and stability of the spindle apparatus, and similar to histone acetylation, are essential for proper spindle formation and kinetochore functioning $(73,74)$. HDAC2 knockout mouse oocytes resulted in hyper-acetylation of H4K16, defective chromosome condensation and segregation, and increased rates of aneuploidy (73). HDAC3 knockout oocytes had higher levels of tubulin acetylation, and impaired spindle assembly, chromosomal alignment, kinetochore-microtubule attachments and chromosomal movement, resulting in higher rates of $\mathrm{MI}$ arrest, and aneuploidy (75).

Sirtuins are another family of cellular deacetylases and Sirt2 in particular also plays an important role in deacetylation of alpha tubules and histone $\mathrm{H} 4 \mathrm{~K} 16$, giving it great importance in normal microtubule and kinetochore function. Sirt2 knockout mouse oocytes show spindle defects, and chromosomal disorganization, and were significantly impaired in completing MI and forming a polar body. Aged mouse oocytes were found to have lower levels of Sirt2, which corresponded to greater defects in forming a meiotic spindle, and aligning chromosomes. What's more fascinating is that overexpression of Sirt2 in aged oocytes by experimental manipulation led to normalized levels of H4K16 and alpha tubulin acetylation levels, and decreased rates of meiotic dysfunction (76).

Other work examined the changes to histone methylation in oocytes with age. There have been some identified decreases in methylation in $\mathrm{H} 3 \mathrm{~K} 9 \mathrm{me} 3, \mathrm{H} 3 \mathrm{~K} 36 \mathrm{me} 2, \mathrm{H} 3 \mathrm{~K} 79 \mathrm{me}$, and H4K20me2 in GV oocytes of old mice when compared to young mice (41). Other researchers found that di- and tri- methylation on H3K4 was decreased in GV oocytes of aged (42-44 weeks) as compared to young (6-8 weeks) mice, and that $\mathrm{H} 3 \mathrm{~K} 4$ dimethylation was increased in MII oocytes of the aged mice. Furthermore, the expression of proteins encoded by the genes containing these histone changes was found to fluctuate with respect to the histone methylation level (42).

These results highlight the fundamental role epigenetics plays in oocyte functioning, and how it may, at least partially, explain the decreased fertility, and increased aneuploidy seen in females of advanced age. They also highlight potential therapeutic interventions that may reduce meiotic error, and improve treatment outcomes.

Histone phosphorylation, ubiquination, and sumoylation in oocytes from older females have not yet been as well examined, but studies looking at gene expression identified a dysregulation 
in genes related to ubiquination in aged oocytes, suggesting dysfunction with age (77).

\section{SUMMARY AND CONCLUSION}

In summary, the existing work on epigenetics and female reproductive aging sheds light on some important cellular mechanisms, while raising many more questions. Manipulating DNMT or HDAC levels in mouse oocytes leads to morbid outcomes, illustrating the critical role these enzymes, and epigenetics in general, play in normal development. A better understanding of their function in normal development, and how they are affected by aging, may lend valuable insight into reproduction and reproductive aging.

MII oocytes and preimplantation embryos of aged mice showed a decrease in DNMT enzymes and methylation levels. Aged mouse oocytes also showed an increase in demethylation enzymes and demethylation cascade intermediates. In contrast, human granulosa cells showed a more nuanced change in methylation with advanced age, shifting toward either extremeincreased methylation in highly methylated regions, and decreased methylation in poorly methylated regions. Histone acetylation was paradoxically decreased in GV oocytes, but increased in MII oocytes of aged mice and humans as compared to young mice. They were shown to play a critical role in normal meiosis, and were also responsive to corrective measures. Finally, histone methylation is decreased in GV oocytes of old mice.

Little has been published, thus far, on the changes to histone phosphorylation, ubiquination, and sumoylation, or the changes

\section{REFERENCES}

1. Bobrowski RA, Bottoms SF. Underappreciated risks of the elderly multipara. Am J Obstetr Gynecol. (1995) 172:1764-7; discussion 1767-70. doi: 10.1016/0002-9378(95)91409-9

2. Armstrong DT. Effects of maternal age on oocyte developmental competence. Theriogenology. (2001) 55:1303-22. doi: 10.1016/S0093-691X(01)00484-8

3. Klein J, Sauer MV. Assessing fertility in women of advanced reproductive age. Am J Obstetr Gynecol. (2001) 185:758-70. doi: 10.1067/mob.2001.114689

4. Demko ZP, Simon AL, McCoy RC, Petrov DA, Rabinowitz M. Effects of maternal age on euploidy rates in a large cohort of embryos analyzed with 24-chromosome single-nucleotide polymorphism-based preimplantation genetic screening. Fert Steril. (2016) 105:1307-13. doi: 10.1016/j.fertnstert.2016.01.025

5. Berkowitz GS, Skovron ML, Lapinski RH, Berkowitz RL. Delayed childbearing and the outcome of pregnancy. $N$ Engl J Med. (1990) 322:659-64. doi: 10.1056/NEJM199003083221004

6. Roberts CL, Algert CS, March LM. Delayed childbearing-are there any risks? Med J Austr. (1994) 160:539-44. doi: 10.5694/j.1326-5377.1994.tb138342.x

7. Simenc GB, Blickstein I, Verdenik I, Bregar AT, Lucovnik M, Tul N. Is forty the new thirty? Population based study of advanced maternal age. J Perinat Med. (2017) 46:247-50. doi: 10.1515/jpm-2017-0060

8. Yeh J, Kim BS, Peresie J. Ovarian vascular endothelial growth factor and vascular endothelial growth factor receptor patterns in reproductive aging. Fert Steril. (2008) 89:1546-56. doi: 10.1016/j.fertnstert.2007.06.032

9. Wise PM, Smith MJ, Dubal DB, Wilson ME, Rau SW, Cashion AB, et al. Neuroendocrine modulation and repercussions of female reproductive aging. Recent Progr Horm Res. (2002) 57:235-56. doi: 10.1210/rp.57.1.235

10. Angell R. First-meiotic-division non-disjunction in human oocytes. Am J Hum Genet. (1997) 61:23-32. doi: 10.1086/513890 to non-histone protein modifications, in oocytes with aging, and the consequences those changes may carry. Histone sumoylation, for example, plays a critical role in mitotic regulation, and spindle assembly in oocytes (78). Epigenetic modifications disrupting normal histone sumoylation functioning can theoretically have severe deleterious effects. Further research is necessary to better understand these changes, and, more specifically, as they occur in human oocytes.

It is also critical to better understand mechanisms of epigenetic changes with age, and the factors that may mitigate or accelerate them. Can biologic or environmental elements that produce oxidative stress, which has been shown to disrupt cellular epigenetics (79), be a factor in determining reproductive longevity? Would it be possible to impede this process, or even correct it, as has been done experimentally using TSA to correct for abnormal acetylation levels? Finally, can epigenetic modifications in aged human oocytes be used to predict an oocyte's embryonic development potential? These questions are just a few of many important areas for clarification, and carry the potential of improving, and fundamentally changing, the care millions of women around the world need and receive.

\section{AUTHOR CONTRIBUTIONS}

IC and DK contributed conception and design of the review. IC searched databases to identify relevant papers, and wrote the first draft of the manuscript. Both authors contributed to manuscript revision, read, and approved the submitted version.

11. Hassold T, Chiu D. Maternal age-specific rates of numerical chromosome abnormalities with special reference to trisomy. Hum Genet. (1985) 70:11-7. doi: 10.1007/BF00389450

12. Keefe DL, Niven-Fairchild T, Powell S, Buradagunta S. Mitochondrial deoxyribonucleic acid deletions in oocytes and reproductive aging in women. Fert Steril. (1995) 64:577-83. doi: 10.1016/S0015-0282(16) 57796-6

13. Eichenlaub-Ritter U, Vogt E, Yin H, Gosden R. Spindles, mitochondria and redox potential in ageing oocytes. Reprod Biomed Online. (2004) 8:45-58. doi: 10.1016/S1472-6483(10)60497-X

14. Felsenfeld G. A brief history of epigenetics. Cold Spring Harb Perspect Biol. (2014) 6:a018200. doi: 10.1101/cshperspect.a018200

15. Morgan HD, Santos F, Green K, Dean W, Reik W. Epigenetic reprogramming in mammals. Hum Mol Genet. (2005) 14:R47-58. doi: 10.1093/hmg/ddi114

16. Sasaki H, Matsui Y. Epigenetic events in mammalian germ-cell development: reprogramming and beyond. Nat Rev Genet. (2008) 9:129-40. doi: $10.1038 / \mathrm{nrg} 2295$

17. Feinberg AP, Tycko B. The history of cancer epigenetics. Nat Rev Cancer. (2004) 4:143-53. doi: 10.1038/nrc1279

18. Jaenisch R, Bird A. Epigenetic regulation of gene expression: how the genome integrates intrinsic and environmental signals. Nat Genet. (2003) 33 (Suppl):245-54. doi: 10.1038/ng1089

19. Friedman N, Rando OJ. Epigenomics and the structure of the living genome. Genome Res. (2015) 25:1482-90. doi: 10.1101/gr.190165.115

20. Bestor TH. The DNA methyltransferases of mammals. Hum Mol Genet. (2000) 9:2395-402. doi: 10.1093/hmg/9.16.2395

21. Yu DH, Ware C, Waterland RA, Zhang J, Chen MH, Gadkari M, et al. Developmentally programmed $3^{\prime}$ CpG island methylation confers tissue- and cell-type-specific transcriptional activation. Mol Cell Biol. (2013) 33:1845-58. doi: 10.1128/MCB.01124-12 
22. Kohli RM, Zhang Y. TET enzymes, TDG and the dynamics of DNA demethylation. Nature. (2013) 502:472-9. doi: 10.1038/nature12750

23. Wu $\mathrm{H}$, Zhang $\mathrm{Y}$. Tetl and 5-hydroxymethylation: a genome-wide view in mouse embryonic stem cells. Cell Cycle. (2011) 10:2428-36. doi: $10.4161 /$ cc.10.15.16930

24. Branco MR, Ficz G, Reik W. Uncovering the role of 5-hydroxymethylcytosine in the epigenome. Nat Rev Genet. (2011) 13:7-13. doi: 10.1038/nrg3080

25. Luger K, Mader AW, Richmond RK, Sargent DF, Richmond TJ. Crystal structure of the nucleosome core particle at 2.8 A resolution. Nature. (1997) 389:251-60. doi: 10.1038/38444

26. Berger SL. Histone modifications in transcriptional regulation. Curr Opin Genet Dev. (2002) 12:142-8. doi: 10.1016/S0959-437X(02)00279-4

27. Imhof A, Wolffe AP. Transcription: gene control by targeted histone acetylation. Curr Biol. (1998) 8:R422-4. doi: 10.1016/S0960-9822(98)70268-4

28. Zhang Y, Reinberg D. Transcription regulation by histone methylation: interplay between different covalent modifications of the core histone tails. Genes Dev. (2001) 15:2343-60. doi: 10.1101/gad.927301

29. Roth SY, Denu JM, Allis CD. Histone acetyltransferases. Ann Rev Biochem. (2001) 70:81-120. doi: 10.1146/annurev.biochem.70.1.81

30. Rose NR, Klose RJ. Understanding the relationship between DNA methylation and histone lysine methylation. Biochim Biophy Acta. (2014) 1839:1362-72. doi: 10.1016/j.bbagrm.2014.02.007

31. Shi Y, Lan F, Matson C, Mulligan P, Whetstine JR, Cole PA, et al. Histone demethylation mediated by the nuclear amine oxidase homolog LSD1. Cell. (2004) 119:941-53. doi: 10.1016/j.cell.2004.12.012

32. Lau PN, Cheung P. Histone code pathway involving H3 S28 phosphorylation and K27 acetylation activates transcription and antagonizes polycomb silencing. Proc Natl Acad Sci USA. (2011) 108:2801-6. doi: 10.1073/pnas.1012798108

33. Tushir-Singh J, Bhatnagar S. In vitro assay to study histone ubiquitination during transcriptional regulation. Methods Mol Biol. (2017) 1507:235-44. doi: 10.1007/978-1-4939-6518-2_17

34. Wotton D, Pemberton LF, Merrill-Schools J. SUMO and chromatin remodeling. Adv Exp Med Biol. (2017) 963:35-50. doi: 10.1007/978-3-319-50044-7_3

35. Biggar KK, Li SS. Non-histone protein methylation as a regulator of cellular signalling and function. Nat Rev Mol Cell Biol. (2015) 16:5-17. doi: $10.1038 / \mathrm{nrm} 3915$

36. Yue MX, Fu XW, Zhou GB, Hou YP, Du M, Wang L, et al. Abnormal DNA methylation in oocytes could be associated with a decrease in reproductive potential in old mice. J Assist Reprod Genet. (2012) 29:643-50. doi: 10.1007/s10815-012-9780-4

37. Qian Y, Tu J, Tang NL, Kong GW, Chung JP, Chan WY, et al. Dynamic changes of DNA epigenetic marks in mouse oocytes during natural and accelerated aging. Int J Biochem Cell Biol. (2015) 67:121-7. doi: 10.1016/j.biocel.2015.05.005

38. Yu B, Russanova VR, Gravina S, Hartley S, Mullikin JC, Ignezweski A, et al. DNA methylome and transcriptome sequencing in human ovarian granulosa cells links age-related changes in gene expression to gene body methylation and $3^{\prime}$-end GC density. Oncotarget. (2015) 6:3627-43. doi: 10.18632/oncotarget.2875

39. Manosalva I, Gonzalez A. Aging alters histone H4 acetylation and CDC2A in mouse germinal vesicle stage oocytes. Biol Reprod. (2009) 81:1164-71. doi: 10.1095/biolreprod.109.078386

40. van den Berg IM, Eleveld C, van der Hoeven M, Birnie E, Steegers EA, Galjaard RJ, et al. Defective deacetylation of histone $4 \mathrm{~K} 12$ in human oocytes is associated with advanced maternal age and chromosome misalignment. Hum Reprod. (2011) 26:1181-90. doi: 10.1093/humrep/der030

41. Manosalva I, Gonzalez A. Aging changes the chromatin configuration and histone methylation of mouse oocytes at germinal vesicle stage. Theriogenology. (2010) 74:1539-47. doi: 10.1016/j.theriogenology.2010.06.024

42. Shao B-G, Wang J, Zhang P-L, Wu Y-C, Jin J, Sang R-J, et al. Aging alters histone $\mathrm{H} 3$ lysine 4 methylation in mouse germinal vesicle stage oocytes. Reprod Fert Dev. (2015) 27:419-26. doi: 10.1071/RD13293

43. Reik W, Dean W. DNA methylation and mammalian epigenetics. Electrophoresis. (2001) 22:2838-43. doi: 10.1002/15222683(200108)22:14<2838::AID-ELPS2838>3.0.CO;2-M
44. Okano M, Bell DW, Haber DA, Li E. DNA methyltransferases Dnmt3a and Dnmt3b are essential for de novo methylation and mammalian development. Cell. (1999) 99:247-57. doi: 10.1016/S0092-8674(00)81656-6

45. Suetake I, Shinozaki F, Miyagawa J, Takeshima H, Tajima S. DNMT3L stimulates the DNA methylation activity of Dnmt3a and Dnmt3b through a direct interaction. J Biol Chem. (2004) 279:27816-23. doi: 10.1074/jbc.M400181200

46. Margot JB, Ehrenhofer-Murray AE, Leonhardt $H$. Interactions within the mammalian DNA methyltransferase family. BMC Mol Biol. (2003) 4:7. doi: 10.1186/1471-2199-4-7

47. Goll MG, Kirpekar F, Maggert KA, Yoder JA, Hsieh CL, Zhang X, et al. Methylation of tRNAAsp by the DNA methyltransferase homolog Dnmt2. Science. (2006) 311:395-8. doi: 10.1126/science.1120976

48. Huntriss J, Hinkins M, Oliver B, Harris SE, Beazley JC, Rutherford AJ, et al. Expression of mRNAs for DNA methyltransferases and methyl-CpG-binding proteins in the human female germ line, preimplantation embryos, embryonic stem cells. Mol Reprod Dev. (2004) 67:323-36. doi: 10.1002/mrd.20030

49. Petrussa L, Van de Velde H, De Rycke M. Dynamic regulation of DNA methyltransferases in human oocytes and preimplantation embryos after assisted reproductive technologies. Mol Hum Reprod. (2014) 20:861-74. doi: 10.1093/molehr/gau049

50. Lucifero D, Mann MR, Bartolomei MS, Trasler JM. Gene-specific timing and epigenetic memory in oocyte imprinting. Hum Mol Genet. (2004) 13:839-49. doi: $10.1093 / \mathrm{hmg} / \mathrm{ddh} 104$

51. Bourc'his D, Xu GL, Lin CS, Bollman B, Bestor TH. Dnmt3L and the establishment of maternal genomic imprints. Science. (2001) 294:2536-9. doi: 10.1126/science. 1065848

52. Hata K, Okano M, Lei H, Li E. Dnmt3L cooperates with the Dnmt3 family of de novo DNA methyltransferases to establish maternal imprints in mice. Development. (2002) 129:1983-93.

53. Kaneda M, Okano M, Hata K, Sado T, Tsujimoto N, Li E, et al. Essential role for de novo DNA methyltransferase Dnmt3a in paternal and maternal imprinting. Nature. (2004) 429:900-3. doi: 10.1038/nature02633

54. Hamatani T, Falco G, Carter MG, Akutsu H, Stagg CA, Sharov AA, et al. Ageassociated alteration of gene expression patterns in mouse oocytes. Hum Mol Genet. (2004) 13:2263-78. doi: 10.1093/hmg/ddh241

55. Pan H, Ma P, Zhu W, Schultz RM. Age-associated increase in aneuploidy and changes in gene expression in mouse eggs. Dev Biol. (2008) 316:397-407. doi: 10.1016/j.ydbio.2008.01.048

56. Steuerwald NM, Bermudez MG, Wells D, Munne S, Cohen J. Maternal agerelated differential global expression profiles observed in human oocytes. Reprod Biomed Online. (2007) 14:700-8. doi: 10.1016/S1472-6483(10)60671-2

57. Szulwach KE, Li X, Li Y, Song CX, Wu H, Dai Q, et al. 5-hmC-mediated epigenetic dynamics during postnatal neurodevelopment and aging. Nat Neurosci. (2011) 14:1607-16. doi: 10.1038/nn.2959

58. Reik W, Dean W, Walter J. Epigenetic reprogramming in mammalian development. Science. (2001) 293:1089-93. doi: 10.1126/science.1063443

59. Santos F, Hendrich B, Reik W, Dean W. Dynamic reprogramming of DNA methylation in the early mouse embryo. Dev Biol. (2002) 241:172-82. doi: 10.1006/dbio.2001.0501

60. Oswald J, Engemann S, Lane N, Mayer W, Olek A, Fundele R, et al. Active demethylation of the paternal genome in the mouse zygote. Curr Biol. (2000) 10:475-8. doi: 10.1016/S0960-9822(00)00448-6

61. Mayer W, Niveleau A, Walter J, Fundele R, Haaf T. Demethylation of the zygotic paternal genome. Nature. (2000) 403:501-2. doi: 10.1038/35000656

62. Lopes FL, Fortier AL, Darricarrere N, Chan D, Arnold DR, Trasler JM. Reproductive and epigenetic outcomes associated with aging mouse oocytes. Hum Mol Genet. (2009) 18:2032-44. doi: 10.1093/hmg/ddp127

63. Kawai K, Harada T, Ishikawa T, Sugiyama R, Kawamura T, Yoshida A, et al. Parental age and gene expression profiles in individual human blastocysts. Sci Rep. (2018) 8:2380. doi: 10.1038/s41598-018-20614-8

64. Nielsen SJ, Schneider R, Bauer UM, Bannister AJ, Morrison A, O’Carroll D, et al. Rb targets histone $\mathrm{H} 3$ methylation and HP1 to promoters. Nature. (2001) 412:561-5. doi: 10.1038/35087620

65. Santos-Rosa H, Schneider R, Bannister AJ, Sherriff J, Bernstein BE, Emre NC et al. Active genes are tri-methylated at K4 of histone H3. Nature. (2002) 419:407-11. doi: 10.1038/nature01080 
66. Kim JM, Liu H, Tazaki M, Nagata M, Aoki F. Changes in histone acetylation during mouse oocyte meiosis. J Cell Biol. (2003) 162:37-46. doi: $10.1083 /$ jcb.200303047

67. Kageyama S, Liu H, Kaneko N, Ooga M, Nagata M, Aoki F. Alterations in epigenetic modifications during oocyte growth in mice. Reproduction. (2007) 133:85-94. doi: 10.1530/REP-06-0025

68. Gu L, Wang Q, Sun QY. Histone modifications during mammalian oocyte maturation: dynamics, regulation and functions. Cell Cycle. (2010) 9:1942-50. doi: 10.4161/cc.9.10.11599

69. Qiao J, Chen Y, Yan LY, Yan J, Liu P, Sun QY. Changes in histone methylation during human oocyte maturation and IVF- or ICSIderived embryo development. Fert Steril. (2010) 93:1628-36. doi: 10.1016/j.fertnstert.2009.03.002

70. Suo L, Meng QG, Pei Y, Yan CL, Fu XW, Bunch TD, et al. Changes in acetylation on lysine 12 of histone $\mathrm{H} 4$ (acH4K12) of murine oocytes during maternal aging may affect fertilization and subsequent embryo development. Fert Steril. (2010) 93:945-51. doi: 10.1016/j.fertnstert.2008. 12.128

71. Demond H, Trapphoff T, Dankert D, Heiligentag M, Grummer R, Horsthemke B, et al. Preovulatory aging in vivo and in vitro affects maturation rates, abundance of selected proteins, histone methylation pattern and spindle integrity in murine Oocytes. PLoS ONE. (2016) 11:e0162722. doi: 10.1371/journal.pone.0162722

72. Akiyama T, Nagata M, Aoki F. Inadequate histone deacetylation during oocyte meiosis causes aneuploidy and embryo death in mice. Proc Natl Acad Sci USA. (2006) 103:7339-44. doi: 10.1073/pnas.0510946103

73. Ma P, Schultz RM. Histone deacetylase 2 (HDAC2) regulates chromosome segregation and kinetochore function via H4K16 deacetylation during oocyte maturation in mouse. PLoS Genet. (2013) 9:e1003377. doi: 10.1371/journal.pgen.1003377
74. Inoue $\mathrm{T}$, Hiratsuka $\mathrm{M}$, Osaki M, Oshimura M. The molecular biology of mammalian SIRT proteins: SIRT2 in cell cycle regulation. Cell Cycle. (2007) 6:1011-8. doi: 10.4161/cc.6.9.4219

75. Li X, Liu X, Gao M, Han L, Qiu D, Wang H, et al. HDAC3 promotes meiotic apparatus assembly in mouse oocytes by modulating tubulin acetylation. Development. (2017) 144:3789-97. doi: 10.1242/dev.153353

76. Zhang L, Hou X, Ma R, Moley K, Schedl T, Wang Q. Sirt 2 functions in spindle organization and chromosome alignment in mouse oocyte meiosis. FASEB J. (2014) 28:1435-45. doi: 10.1096/fj.13-244111

77. Grondahl ML, Yding Andersen C, Bogstad J, Nielsen FC, Meinertz H, Borup R. Gene expression profiles of single human mature oocytes in relation to age. Hum Reprod. (2010) 25:957-68. doi: 10.1093/humrep/deq014

78. Huang CJ, Wu D, Jiao XF, Khan FA, Xiong CL, Liu XM, et al. Maternal SENP7 programs meiosis architecture and embryo survival in mouse. Biochimica et biophysica acta. Mol Cell Res. (2017) 1864:1195-206. doi: 10.1016/j.bbamcr.2017.03.005

79. Guillaumet-Adkins A, Yanez Y, Peris-Diaz MD, Calabria I, Palanca-Ballester C, Sandoval J. Epigenetics and Oxidative Stress in Aging. Oxidat Med Cell Long. (2017) 2017:9175806. doi: 10.1155/2017/9175806

Conflict of Interest Statement: The authors declare that the research was conducted in the absence of any commercial or financial relationships that could be construed as a potential conflict of interest.

Copyright (c) 2019 Chamani and Keefe. This is an open-access article distributed under the terms of the Creative Commons Attribution License (CC BY). The use, distribution or reproduction in other forums is permitted, provided the original author(s) and the copyright owner(s) are credited and that the original publication in this journal is cited, in accordance with accepted academic practice. No use, distribution or reproduction is permitted which does not comply with these terms. 